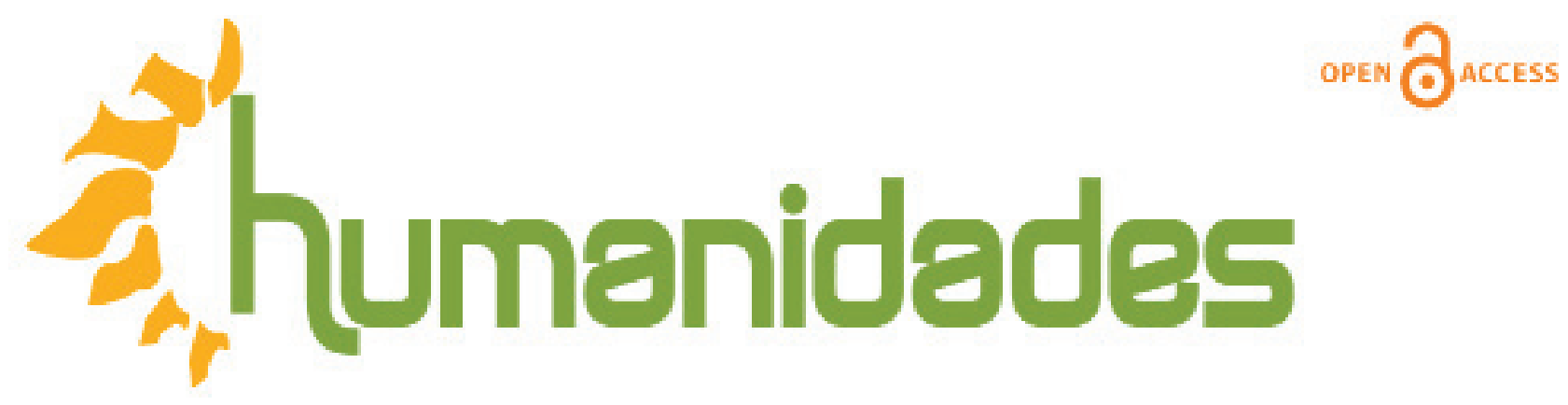

Revista de la Escuela de Estudios Generales, Universidad de Costa Rica

Enero-julio, 2019 •Volumen 9, número 1 • EISSN 2215-3934•pp. 1-30

Recibido: 26-Abril-2018 Aceptado: 21-Agosto-2018

\title{
Populismos y populistas: las evoluciones de un paradigma entre México y Rusia
}

DOI: https://doi.org/10.15517/h.v9i1.35286

\section{Lucia Picarella y Carmen Scocozza}

Ph.D.s en Teoría e Historia de las Instituciones Políticas Comparadas por la Università degli Studi di Salerno, Italia. Investigadoras Asociadas. Profesoras en la Maestría Internacional en Ciencia Política Universidad Católica de Colombia-Università degli Studi di Salerno. Picarella es autora de los títulos 1 y 2; Scocozza de los títulos 3 y 4; introducción y conclusión son obra conjunta.

Correo electrónico: 1picarella@ucatolica.edu.co y cscocozza@ucatolica.edu.co

Todos los derechos reservados. Universidad de Costa Rica. Esta revista se encuentra licenciada con Creative Commons. Reconocimiento-NoComercial-SinObraDerivada 3.0 Costa Rica. Correo electrónico: humanidades@ucr.ac.cr/ Sitio web: http://revistas.ucr.ac.cr/index.php/ humanidades 


\title{
Populismos y populistas: Las evoluciones de un paradigma entre México y Rusia
}

\section{Resumen}

El artículo analiza las tendencias populistas que subyacen en el complejo panorama político actual, en particular haciendo referencia al caso mexicano y ruso. A pesar de la dificultad de definir un fenómeno tan ambiguo, parece oportuno considerar las estrechas relaciones entre el populismo y los procesos de degeneración democrática que caracterizan diferentes países en el actual escenario mundial. A través de una inicial reconstrucción histórica, las autoras reflexionan sobre la evolución que ha tenido el fenómeno en el curso de los siglos perdiendo gran parte de su connotación originaria. Una involución ideológica que se traslada al ámbito institucional y que hoy en día se presenta en forma de hiperpresidencialismo y de una extrema personalización de la política. Asumiendo las innegables diferencias existentes entre los dos casos objeto de estudio, el trabajo considera cómo la realidad latinoamericana y, a la vez, la rusa, pueden representar un caso ejemplificativo de la crisis del tradicional andamio democrático y la afirmación de un liderazgo carismático, núcleo central de esta nueva dinámica populistaplebiscitaria.

\section{Populism and Populists: the Evolution of a Paradigm Between Mexico and Russia}

\begin{abstract}
The article analyzes the populist tendencies that underlie the current complex political panorama, in particular referring to the Mexican and Russian case. Despite the difficulty of defining such an ambiguous phenomenon, it seems appropriate to consider the strong relations between populism and the processes of democratic degeneration that characterize different countries in the current world scenario. Through an initial historical reconstruction, the authors reflect on the evolution of the phenomenon over the centuries, losing much of its original connotation. An ideological involution that is transferred to the institutional sphere and that nowadays is presented in the form of hyperpresidentialism and an extreme personalization of politics. Assuming the undeniable differences between the two cases of study, the work considers how the Latin American reality as well as the Russian case can represent an exemplary case of the crisis of the traditional democratic scaffolding and the affirmation of a charismatic leadership, central nucleus of this new populist-plebiscitary dynamics.
\end{abstract}

\author{
Palabras clave: \\ populismo, \\ hiperpresidencialismo, \\ personalización de la \\ política, México, Rusia
}
Keywords:
populism, hyperpresidentialism, personalization of politics, Mexico, Russia




\section{Introducción}

Los significativos desafíos que hoy en día están cruzando el tablero internacional, sometiendo los sistemas políticos contemporáneos a duras transformaciones, impulsan a reflexionar sobre las tendencias que subyacen la incertidumbre que sopla en el complejo panorama político actual. Indudablemente, entre estas dinámicas, se coloca la espinosa cuestión de la personalización y del populismo, controvertidos ámbitos teóricos que sin embargo tienen relevantes efectos en la arquitectura político-institucional democrática convirtiéndose, de facto, en la praxis política de la modernidad, evidenciando contemporáneamente la crisis del tradicional andamio democrático y la necesidad de nuevos paradigmas y horizontes de acción política. Insertándonos en esta línea, el presente artículo tratará de comparar, según una perspectiva histórico-politológica, dos casos de estudios que, prima facie, no parecen tener puntos de contacto, pero que a la inversa, presentan un mínimo denominador común.

Más en particular, asumiendo la dificultad de movernos en el laberinto de conceptos fluidos - propiamente los de personalización política carismática y de populismoy de contextos diferentes, el objetivo será contrastar las recientes evoluciones de las formas de populismo latinoamericano, en particular, el populismo mexicano y, además, el ruso. Un análisis que posee su hilo conductor es la presencia de dos populismos agrarios, símbolos de las luchas procedentes de este sector en contra de las desigualdades económicas, cuyo núcleo, aunque en momentos diferentes, está representado por el lema: Tierra y Libertad. Luchas que reconocían en el liderazgo carismático o en el aparato partidista la posibilidad de derramar sus reivindicaciones, y cuyas metamorfosis confluyeron, en ambos casos, en una fuerte presidencialización político-institucional y en una relevante centralización estatal. Alteraciones que, por lo tanto, nos permitirán evaluar la influencia de las mismas en consideración de los diferentes resultados obtenidos en ambos contextos en términos de configuración del aparato y de la praxis política-institucional, así como las consecuentes "desviaciones" de los ideales formalmente establecidos y, además, tanto la singularidad del caso mexicano en comparación con las categorías clásicas del populismo latinoamericano, así como del caso ruso en Europa. 


\section{Personalización política y populismo: una síntesis teórica}

Indiscutiblemente, la significativa crisis de legitimidad - y las consecuentes apelaciones a la necesidad de un fuerte cambio- que en los últimos años está apretando la contemporánea democracia representativa, ha empujado y fomentado a la politología a penetrar el complejo y vago ámbito de los multifacéticos desvíos de los sistemas políticos. Con el fin de entender la sutil cuestión de las transformaciones estructurales de las actuales democracias, es indispensable considerar la relevante laceración que se ha producido entre representantes y representados ${ }^{1}$, un binomio nuclear a la inversa para alimentar el circuito responsiveness/accountability/ decisión-making, cuyo desvanecimiento provoca una exacerbación del impasse democrático, y pues, una situación de deslegitimación político-institucional que constituye el humus fértil para el fortalecimiento de las dinámicas de personalización política carismática y de populismo.

Se trata, de hecho, de dos tendencias caracterizadas por una relevante dificultad teórico-conceptual que pueden fuertemente entrelazarse entre ellas mismas, cuyos límites se matizan - en la práctica- en el interior de sistemas políticos guiados por carismáticos liderazgos que, sobre todo hoy en día, a través del patrocinio de puntuales técnicas mediáticas, pueden llegar a personificar el mito y encarnar su propio pueblo. Un concepto, este último, que evidentemente representa nuestra clave de lectura, ya que si bien es verdad que no necesariamente una tendencia desemboca en la otra; sin embargo, una identificación total ${ }^{2}$ entre un liderazgo carismático y su pueblo representa la condición preliminar para colmar vacíos institucionales, y el resultado de la consiguiente proyección de la instaurada relación directa líder/pueblo/poder en una clara función anti-establishment, será la plena justificación de la esencialidad del líder, símbolo de la soberanía y de la voluntad popular.

Bien se entiende, entonces, que el elemento de heterogeneidad y de fluidez que conforma estas nociones procede, claramente, de la dificultad de converger hacia una única definición ${ }^{3}$ e, igualmente, hacia una concertación en referencia al núcleo en el cual se han insertado y evolucionado las eventuales y diferentes tradiciones 
(Zanatta, 2004, p. 387; Venturi, 1972; Canovan, 1981; Kazin, 1995), de esta manera, se caracterizan las dinámicas de personalización política y de populismo como varios de los análisis más controvertidos dentro de la ciencia política.

En la perspectiva planteada en esta reflexión, a saber, la consideración de personalización política carismática y del populismo como dos tendencias que, de facto, contribuyen de manera significativa a la transformación de la cara de las democracias contemporáneas (Picarella, 2016), evidentemente se declinan las generalizaciones rápidamente mencionadas. De hecho, en el actual panorama de inquietud reformadora, que conduce a hablar de post-democracia y post-política proponiendo como solución alternativa una roussoniana forma de democracia directa, no es tan infrecuente la aparición de liderazgos, que se presentan como outsiders, capaces de resolver las frustraciones del pueblo. Pero, es propiamente en este punto que, según nuestra opinión, es oportuno enfocar la atención, porque si por un lado, justamente en las reivindicaciones agrarias en contra de las desigualdades, se puede encontrar el mínimo común denominador de las distintas variantes de populismo; sin embargo, por el otro lado, es fundamental preguntarse cómo, en la praxis, estas dinámicas han evolucionado hasta distorsionar los nobles ideales iniciales.

Rápidamente, en la segunda mitad del siglo XIX se asiste al surgimiento simultáneo de los populismos estadounidense y ruso, ambos conformados como una reacción originaria del campesinado, articulados como movimientos -respectivamente- de y para campesinos, de molde libertario/progresistas, tendientes a influenciar el poder público a través del levantamiento de tipo bottom-up y la promoción de las necesidades del mundo agrario en la arena político-institucional.

De hecho, las reivindicaciones de los pequeños cultivadores norteamericanos, estremecidos por los fuertes cambios procedentes de la progresiva industrialización que estaba caracterizando la sociedad estadounidense en aquella temporada, confluyeron en la constitución de dos organizaciones que lograron fundir las expectativas del sector agrario en la generación de una relevante red socio-política, y que sin duda, fueron precursoras de las luchas hacia una mayor democracia llevadas a cabo por el más famoso People's Party ${ }^{4}$ Ideales de mayores niveles de libertad e igualdad que, como se ha mencionado, permean contemporáneamente la tradición del populismo ruso, propiamente artífice del ideal-tipo populista, impulsado por 
las duras críticas al régimen zarista por parte de eminentes intelectuales enfocados sobre la idea de la construcción de una sociedad igualitaria mediante la realización de una comuna campesina.

Reflexiones teóricas que, por un lado, evidencian la diferencia con el populismo norteamericano, ya que en el caso ruso estamos frente a un movimiento constituido por intelectuales revolucionarios para los fines de estallar una revolución capaz de instaurar una nueva sociedad, mientras que, por el otro lado, y en consideración del nivel de acción práctica, el movimiento Tierra y Libertad (Zemlya $i$ Volya) subrayaba nuevamente la relevancia, proporcionada por los teóricos del mismo, de la franja campesina reconocida como el puro testimonio del pueblo. ${ }^{5}$

Pues, si comparamos con estos dos tipos de populismos la corriente que se desarrolló en la región latinoamericana en la primera mitad del siglo XX, lo que de repente se destaca es una diferente estructuración que parece moverse sobre líneas bien definidas y opuestas a los dos casos originarios, a saber: la presencia de un claro y fuerte liderazgo político que canalizaba las reclamaciones de frentes/coaliciones policlasistas ${ }^{6}$ y que, contemporáneamente, se regía sobre una movilización top-down de los mismos, llegando a ocupar definitivamente el espacio político mediante un partido gobernante, en algunos casos, produciendo un cambio de régimen al personificar la arena político-institucional con el caudillo. ${ }^{7}$

\subsection{La variante latinoamericana: el caso mexicano}

Asumiendo, claramente, las diferencias que transcurren entre los heterogéneos escenarios de la región latinoamericana, y de igual manera, el diferente desarrollo del populismo en el interior de los mismos, como ya se ha mencionado, el punto de encuentro seguirá siendo también, en este caso, el terreno agrario. En general, si de hecho se subraya el surgimiento de la tradición populista latinoamericana a partir de las crisis agrarias que marcaron el ingreso de la región en la etapa de urbanización/industrialización, sin embargo, cabe destacar que, según Hennessy (1970), parece que la ruta de la subsiguiente evolución de esta tradición se ha paradójicamente caracterizado por el abandono del mundo campesino y por la apatía cerca de la lucha en contra del statu-quo. Efectivamente, penetrando 
más esta cuestión y acercándonos al primer término de nuestra comparación, considerando el populismo como el resultado de un proceso de secularización y, además, colocándolo en el continuo movimiento de masas-luchas de clases, ${ }^{8}$ un caso de prominente interés es representado por el populismo mexicano, hijo de la revolución.

En particular, exactamente en el momento en que el sector agrario dejó de ser el alfiler de la economía del régimen ruso, suplantado por el ideal de la revolución del proletariado, que dejaba de lado el núcleo teórico primordial del populismo ruso, en México, detonaba la revolución zapatista cuyas reivindicaciones, recibiendo y asimilando el lema Tierra y Libertad de la organización populista rusa, desembocaron en el Plan Ayala ${ }^{9}$ y empujaron hacia el logro la reforma agraria y la institucionalización de estas mismas luchas en la Constitución de 1917, pionera en el reconocimiento de derechos sociales y laborales. ${ }^{10}$

Sin duda, el campesinado representó la base de la resistencia a la lógica capitalista, ampliamente desarrollado durante el porfirismo, un núcleo duro que fundamentó los movimientos de masas que plegaron propiamente esta lógica explotativa a la revolución. ${ }^{11}$ Pues, propiamente el ímpetu abrumador de la revolución popular, marca los rasgos iniciales del populismo mexicano, ya que la consideración de variables tales como la masiva y espontanea participación popular, la promoción de una proto-democratización a favor del pueblo y en contra de cualquier forma de oligarquía dominante, lo clasifican - junto con la tradición rusa y norteamericana - como una forma de "populismo positivo".

Entonces, propiamente el contexto histórico-político mexicano se convierte en un componente clave para los fines de entender tanto la peculiaridad del surgimiento de las dinámicas populistas en este escenario, como las evoluciones subsiguientes. Primero, como ya se ha anticipado, la tipicidad mexicana reside en el hecho de que el populismo hunde sus raíces en la revolución, es un segmento de ella y de su capacidad de derrotar a las élites. 
Ahora bien, con la finalización de esta revolución, podemos empezar a considerar las transformaciones de esta tendencia, ya que la necesidad de enfrentar la gran crisis de los años treinta del siglo XX dio lugar en la región latinoamericana a las formas de populismo reconocidas como clásicas. Sin embargo, nuevamente podemos subrayar unas relevantes diferencias entre los casos que caen en esta categoría - y que según nuestra opinión son fundamentales para comprobar la tipicidad mexicana - ya que la praxis política que caracterizó al cardenismo marcó profundamente a México en un sentido estructural.

De hecho, si por un lado, la fusión entre la realización de las aspiraciones de la lucha revolucionaria en materia agraria con las nuevas demandas post-crisis permitió el estallido de la popularidad de Cárdenas, ${ }^{12}$ por el otro lado, evidentemente su estilo político, de todos modos considerado por algunos autores como autoritario, ${ }^{13}$ dispuso una forma de populismo institucional; es decir, ya no totalmente dependiente del líder -como los otros dos casos de populismo clásicos: peronismo y varguismo-, sino plasmada y amalgamada en la estructura organizativa del Estado.

Una institucionalización que, claramente, perdura en las tendencias de populismo fundado en la encarnación/mitificación del liderazgo, decretando un estatus quo dominante en el cual emerge un protagónico papel estatal, y cuya mecánica político-institucional se fundamentará sobre el rol guía del mismo Estado en todos los ámbitos.

Así pues, es una tendencia que sin duda ha sido favorecida por las características que subyacen en el sistema político mexicano, a menudo definido como corporativo, patrimonial, orientado al clientelismo, elementos a su vez, favorecidos por una fuerte verticalización del poder y la ausencia de canales institucionales de participación que, claramente, no han favorecido el desarrollo de una cultura política activa (Zermeño, 1996; Córdova, 1974; Cansino-Covarrubias, 2006, p. 13). Entonces, bien se entiende cómo esta síntesis socio-político-institucional ha favorecido el injerto de una articulación Estado-sociedad que, si por un lado ha moldeado la fisionomía del aparato político mexicano, por el otro, ha impulsado orientaciones de tipo populista que, sin embargo, así como en el resto del mundo, se han desviado en cuanto a los propósitos originarios de estas tradiciones. 
Una breve panorámica puede más fácilmente evidenciar lo que acabamos de mencionar, ya que al populismo clásico de Cárdenas, le seguirá en los años setenta una forma de populismo económico, llevado a cabo por Echeverría y López Portillo, quienes siguieron la pauta autoritaria para enfrentar un duro periodo de crisis a través de control-manipulación, implementado mediante la combinación gasto público/fortalecimiento del Ejecutivo/asistencialismo. A esta etapa, le siguió el neopopulismo salinista, cuyos rasgos se alinean perfectamente a la ola que caracterizó a América Latina en los últimos dos decenios del siglo XX, ya que el mínimo común denominador de estos gobiernos fue el colapso de la institucionalidad vs. el establecimiento de la legitimidad a través de la personalización política. ${ }^{14}$

El liderazgo carismático se convierte, por lo tanto, en el núcleo de esta dinámica populista-plebiscitaria, cuyo objetivo es propiamente la desaparición de los mecanismos institucionales detrás del líder para que, una vez logrado el apoyo político-electoral a través de una fuerte personificación y mediatización de la arena política, él mismo pueda plasmar el Estado a su imagen con reformas que, en el caso latinoamericano, fueron principalmente económicas y de molde liberal.

Finalmente, en la actualidad, estos elementos se mezclan con nuevas variables, subrayando por todo lado la presencia de una forma de populismo post-democrático, en donde personalización-mediatización, carismáticos liderazgos y estrategias electorales, se funden con discursos fuertemente anti-políticos/anti-establishment, el todo encarnado nuevamente por personalidades fuertes. Varios son los ejemplos que se enmarcan en este sentido, a saber: las fuertes desviaciones hacia la extrema derecha que están caracterizando los llamados populismos europeos; ${ }^{15}$ o por el otro lado del océano, las estrategias llevadas a cabo por el Presidente Trump que parecen conformar una variante populista 'híbrida' (Petrone-Picarella, 2018), también, el mismo Presidente mexicano Peña Nieto, quien para su candidatura a la presidencia de la república realizó una personalizada campaña totalmente fundada sobre técnicas de marketing político y relevante implementación de e-strategies, ${ }^{16}$ por último, regresando al otro extremo de occidente, sin duda, los mecanismos fundamentales puestos en marcha por el putinismo. 


\section{El origen del populismo ruso}

Como ya se ha anticipado, no deja lugar a dudas que cada reflexión sobre el populismo empieza haciendo referencia al origen de un movimiento que se hunde en la realidad rusa de la mitad del siglo XIX, cuando los intelectuales radicales empezaron a advertir con urgencia la necesidad de un rescate de la población campesina. Bajo el nombre de populismo ruso se considera una variada orientación ideal que se difundió entre estudiantes e intelectuales para promover en el país un socialismo agrario o, mejor dicho, una "vía rusa" hacia el socialismo contra la unilinealidad del desarrollo humano.

Si parece natural referirse a la expresión rusa narodnicestvo para identificar las raíces de un movimiento que, por primera vez, pone al pueblo en el centro de sus reivindicaciones, un análisis más profundo permite entender la transformación de un término que ha perdido la originaria connotación para convertirse en algo muy diferente.

En general, ya en los años cuarenta del siglo XIX, frente a la política autoritaria de Nicolás I, grupos de jóvenes intelectuales habían encontrado en la especulación filosófica la sola alternativa al inmovilismo del imperio y habían empezado a interrogarse sobre la oportunidad de instaurar un diálogo con el resto de la sociedad, totalmente ajena a los fermentos revolucionarios que cruzaban a Europa en esos años. $^{17}$

La llegada al poder de Alejandro II y la abolición de la servidumbre de la gleba en 1861 representó la esperanza de una posible revolución centrada en el campesinado. Este primer movimiento heterogéneo que, como dice Isaiah Berlin (1961, p. 674), fue «una masa inestable de grupos pequeños independientes, de conspiradores y sus seguidores, que a veces se unían en una acción común, y más a menudo operaban de manera aislada», se caracterizaba por la común oposición al zar y la mitificación de los campesinos, a los cuales se les imputaba la transformación de la arcaica sociedad rusa. ${ }^{18}$ 
Si el pueblo representaba la principal fuerza inspiradora del originario movimiento revolucionario ruso, desafortunadamente, esta pretensión de ser el portavoz de sus necesidades y aspiraciones se enfrentaba con una realidad bastante diferente; las dificultades de comunicación por la censura existente en el vasto imperio y la incapacidad de entenderse entre una intelectualidad que miraba a la experiencia occidental imaginando un futuro desarrollo revolucionario en la misma Rusia, y a la vez, el resto de la sociedad interesada en su supervivencia más que en estériles debates teóricos, representaba el principal obstáculo para un auténtico diálogo entre las partes.

Diálogo que pareció ser siempre más urgente en el momento en que el fracaso de las revoluciones de 1848 en Europa representó la oportunidad de reconsiderar los límites de una agitación política sin una contemporánea revolución social y de imaginar para Rusia un destino diferente, donde su peculiaridad histórica y la ausencia de tradiciones radicadas podía representar el elemento de fuerza para realizar un cambio radical y una verdadera trasformación social. ${ }^{19}$ Partidario de esta visión y su principal teórico fue indudablemente Aleksandr Herzen, definido por Franco Venturi (1972, v. 1, p. 3) como el "creador del populismo". El exiliado ruso, desde 1852, año en que decidió trasladarse a Londres, empezó una importante actividad como periodista la cual culminaría con la difusión de la revista "Kolokol" (La Campana), publicada entre el 1857 y $1867^{20}$ y en la que colaboró su amigo Ogarev; todos sus esfuerzos fueron dirigidos hacia la ampliación de la participación política de los rusos en un debate que tenía como objetivo último la reforma social del imperio. Esta voluntad de llegar a las fuerzas externas de los limitados círculos de la intelectualidad rusa representa «la prueba de lo que, de hecho, será la dirección hacia la cual tenderá el esfuerzo de los populistas en las dos décadas siguientes» (Venturi, 1972, p. 75).

En particular, como ya se ha anticipado, la llegada al poder de Alejando II representó un estímulo adicional en la medida en que "el zar reformador" fomentaba nuevas esperanzas sobre una posible colaboración entre gobierno, intelectuales y pueblo, para mejorar las condiciones de vida en el imperio. Si esto, por un lado, significó atenuar el componente revolucionario en favor de un proceso de reformas graduales, por el otro, desde las páginas de la revista, Herzen renovó la invitación de "ir al pueblo", dedicarse a sus necesidades y penetrar en ello. 
Sin embargo, como también aclara Franco Venturi (1972, p. 3), las contradicciones del pensamiento herzeniano y el abandono de las ideas revolucionarias en favor de una temporánea confianza en el nuevo zar, convirtieron a Herzen en un personaje discutido que, «cuando en los años sesenta el populismo se convertirá en una corriente política (...) será olvidado y renegado, por haber trasmitido a la nueva generación su vida de investigador y pensador crítico, y no un pensamiento concluido». Por esta razón, su herencia se tiene que entender en un sentido más amplio: él no dejó una organización, sino una nueva manera de entender la realidad circundante, un ideal político, una necesidad de informar y educar el pueblo para convertirlo en el principal responsable de su futuro. ${ }^{21}$

El fracaso de cualquier intento de poner el "Kolokol" como guía de la principal organización populista Zemlja y Volja (Tierra y Libertad), fundada en 1861 por SernoSolovévic, y las divergencias con los demócratas rusos más radicales, Černyševskij, Dobroljubov y Bakunin, solo para mencionar algunos, representó el comienzo del declive de Herzen y de una nueva etapa en el cual el populismo trató de pasar de la especulación teórica a la acción revolucionaria. ${ }^{22}$ Esta primera organización no tuvo particular éxito, sin embargo, «es importante como anillo de conjunción entre la dos fases de las ideas y de la acción» ${ }^{23}$ ( Seton-Watson, 1971, p. 337).

La actividad de propaganda siguió con un nuevo grupo, la Organización, creado en 1865 por Išutin; la decepción por la promesas incumplidas y las reformas parciales de esos años llevó a un desemboque siempre más radical del movimiento, hasta llegar a considerar el terrorismo como la opción más viable para despertar la conciencia del pueblo y crear las condiciones para una insurrección general. ${ }^{24}$

Se iba entonces delineando un escenario complejo donde, por un lado, empezaron a organizarse ataques terroristas, de hecho, en 1866 fracasó un intento de asesinato contra el zar; por el otro. la dura reacción por parte del gobierno y la consiguiente ola de represión impuso una reflexión sobre la eficacia y las perspectivas de esta corriente revolucionaria. Regresó al centro del debate la necesidad de realizar un apostolado para llegar a los sectores hasta ahora excluidos de una verdadera educación política; así, entre 1873 y 1874 se puso en práctica la exhortación herzeniana de "ir al pueblo" (v narod) con cientos de jóvenes que se mudaron a los pueblos para predicar entre los campesinos las ideas revolucionarias. En este caso, 
también es difícil hablar de un grupo homogéneo porque había posiciones bastante diferentes entre aquellos que querían politizar a los campesinos y empujarlos a levantarse, y los que veían en esta experiencia una oportunidad para conocer la realidad campesina y sentar, a través de esta vida en común, las bases para crear una visión compartida sobre el futuro de Rusia. En general, a pesar del entusiasmo de estos jóvenes, el contexto en el cual actuaban era dificultoso: los revoltosos fueron objeto de persecución por parte de la policía, juzgados y condenados, mientras que la mayoría campesina parecía bastante insensible a la propaganda revolucionaria.

El convencimiento sobre que fuera necesario no solo educar al pueblo, sino aprender del pueblo, llevó a la decisión de organizar de manera más estructurada el movimiento para tener algunas posibilidades de éxito; fue así que nació el primer partido revolucionario de Rusia ${ }^{25}$ que retomó el antiguo nombre Zemlja $i$ Volja y se comprometió a realizar una obra de educación al pueblo que no fuera tan discontinua, sino preparada a través de pequeños grupos que vivían con los campesinos y, a la vez, participaban con ellos en trabajos útiles socialmente. Con la realización de pequeños levantamientos en las provincias del imperio se lograron algunos resultados positivos, sin embargo, la experiencia directa en el campo ayudó a entender que las condiciones no eran maduras para convertir a un instituto como el obščina en el punto de partida de un nuevo orden socialista; los campesinos eran mucho menos revolucionarios de lo que se había imaginado y además era casi imposible convertir en una sola fuerza unitaria la dispersa población de los pueblos rusos.

Desde esta perspectiva empezó a parecer más viable una acción de proselitismo en los centros urbanos, donde los pobres de las ciudades, provenientes de los campos, que llegaban a trabajar en las fábricas resultaban más receptivos y participativos. Por otra parte, los revolucionarios se dedicaron más intensamente a la organización de atentados, considerándolos el arma más eficaz para golpear la estructura piramidal del gobierno: como el poder estaba concentrado en las manos de pocos hombres, acabar con ellos parecía la manera más rápida para favorecer un cambio de la odiosa autocracia rusa. La nueva organización Narodnaja Volia (la voluntad del pueblo) nacida en 1879 hizo, así, del asesinato del zar el objetivo principal de su acción; objetivo que se llevó a cabo el primero de marzo de 1881 y que puede considerarse como el comienzo del declive del movimiento populista, 
el cual había imaginado, con este atentado, el inicio de una insurrección popular que no se realizó. Desde ese momento empezó una fuerte represión y se descartó cualquier posibilidad de reformas a través de un diálogo entre autocracia y fuerzas progresistas. $^{26}$

\subsection{Populismo y Putinismo}

La inicial reconstrucción sobre el primer populismo ruso parece importante para entender cómo este ha sido una experiencia anómala fundada en la idealización de un pueblo por parte de intelectuales que en realidad no conocían el objeto de su propia especulación. Solo haciendo referencia a una definición más amplia de populismo «que inscribe en éste todas las experiencias políticas, sociales o ideológicas que apelan a la categoría de "pueblo" o explotan de alguna manera el descontento de los de abajo con los de arriba, de los pobres con los ricos, de los sin poder con los empoderados» (Ulianova, 2003, pp. 159-160), solo así, podemos encontrar algunos elementos en común con la realidad actual. Faltaba en el movimiento originario un elemento propio del populismo contemporáneo: un fuerte liderazgo carismático capaz de establecer con la comunidad una relación directa y sin intermediarios. Por esta razón, al final del siglo XX en la misma Rusia se introdujo un nuevo término, popoulizm, para definir fenómenos políticos caracterizados por un fuerte líder que se comunica directamente con las masas utilizando muchas veces temas demagógicos y xenófobos. ${ }^{27}$ Frente a un debate más amplio sobre la relación que hay entre el populismo y los procesos de degeneración democrática que caracterizan diferentes países en el actual escenario mundial, indudablemente, la progresiva involución autoritaria de la Federación Rusa nos invita a interrogarnos si la fuerte personalización del poder, llevada a cabo por Putin, puede ser considerada una forma de populismo.

Antes de profundizar este aspecto, parece oportuno señalar cómo algunos elementos del populismo se encuentran a lo largo de toda la historia rusa. Si pensamos en la relación directa entre el líder y los gobernados por encima de los grupos intermedios, en la apelación a los elementos de la cultura tradicional hasta llegar a su mistificación, y en la connotación mesiánica de los nuevos proyectos políticos alternativos hasta llegar a la esclerosis política del país donde el fenómeno se presenta, nos damos cuenta que estas manifestaciones han acompañado, a menudo, 
los cambios radicales vividos en la compleja historia rusa. Apelaciones al pueblo en las que, en la mayoría de los casos, este no es un verdadero interlocutor sino un falso objeto, una masa indistinta a la cual se hace referencia en los momentos cruciales de formación de este estado centralizado en ausencia de instituciones fuertes y radicadas (Ulianova, 2003, pp. 159-174).

Un país donde históricamente la estructura social y cultural se hunde en la autocracia y la autoridad recae sobre una sola persona sin ningún límite. Considerada la extensión territorial, la rigidez del clima y las distancias significativas que impedían contactos constantes entre las ciudades, en el imperio no se consolidó nunca un comercio nacional ni tampoco una clase media o una cultura urbana. Bajo estas condiciones faltó el adecuado desarrollo de aquellas instituciones que en Occidente representaron, en el curso de los siglos, una limitación fundamental para el poder del rey: una nobleza, una clase media independiente y la propiedad privada de la tierra.

La ausencia de cuerpos intermedios por un lado y la vastedad del territorio por el otro, favorecieron por sí mismos un gobierno fuertemente centralizado; el país, desprovisto de defensas naturales y sujeto en el curso de los siglos a incursiones extranjeras, desarrolló, en consecuencia, una estructura militar concentrada (Scocozza, 2017).

En esta realidad peculiar, todas las grandes transformaciones han sido siempre asociadas a la acción de un único protagonista en una peligrosa relación entre el destino del país y el hombre que lo gobierna en un momento dado. Esta fuerte centralización y personalización del poder ha determinado entonces una situación en donde, como ya lo destacó un controvertido autor ruso del siglo XIX, Konstantin Leontev, el sentimiento nacional encontró en Rusia su principal expresión de lealtad a la monarquía. En su opinión, el "zarismo centralizador" permitió a Rusia realizar un Estado fuerte donde las revueltas fueron siempre dominadas por profundos sentimientos conservadores, cuyo último objetivo era el deseo de restaurar una relación más directa entre el pueblo y el soberano, contra la aristocracia y el clero. ${ }^{28}$

Estas premisas parecen importantes para entender que la crisis democrática que está viviendo Rusia en los últimos tiempos no puede ser considerada solo una consecuencia de las tentaciones autoritarias del actual presidente, sino en cuanto 
producto de una historia de frustraciones y decepciones de un pueblo que ha preferido descargar sobre el gobernante la responsabilidad del proceso de toma de decisiones a cambio de seguridad y protección.

A la luz de estas consideraciones, volvemos al interrogativo inicial sobre la posibilidad de encasillar el fenómeno Putin en la categoría de populismo. No deja lugar a dudas que en el presidente ruso se encuentran varios elementos comunes a todos los líderes populistas: el carisma y la capacidad de promover un constante diálogo con el pueblo, diálogo en el cual abundan elementos nacionalistas y la evocación del pasado imperial como respuesta al descontento popular; sin embargo, no se puede subestimar el hecho de que Vladimir Putin no llegua al poder desde una plataforma populista, sino como sucesor designado por el anterior jefe de estado.

Asimismo, si en el resto del mundo el populismo se presenta como "una elección democrática en favor de un menor liberalismo" (Oliker, 2017, p. 18), en el caso de Rusia no se trata de un deterioro de las instituciones democráticas, en la medida en que, en el imperio nunca se ha afirmado un sistema de pesos y contrapesos análogo a los otros países occidentales.

Más allá de estas diferencias que nos permiten hablar de un "populismo imperfecto", no se puede dejar de considerar que la Federación Rusa parece el terreno ideal para la proliferación del populismo. En los discursos del presidente hay temas recurrentes bastante afines al discurso populista: la defensa de lo que en Rusia se define como "democracia soberana"; la apelación a los valores tradicionales para hacer frente a los problemas sociales y el patriotismo para favorecer la unidad nacional (Casula, 2013, pp. 3-15).

Es importante destacar la reivindicación de una democracia "a la rusa", donde el ejercicio del poder se identifica con un vértice personalizado que se legitima por sí mismo y no necesita aprobación por parte de actores externos. ${ }^{29}$ Conceptos que se definen de manera negativa: democracia contra las injerencias externas y afirmación de valores tradicionales y patrióticos contra la occidentalización como evolución inevitable. Aparece, entonces, la afirmación de lo que Zanatta (2013, p. 25) define como un "liderazgo maniqueo" donde el líder tiende a «exasperar una visión maniquea del mundo y de las relaciones sociales como terreno de lucha entre bien y mal, entre amigos y enemigos, sin ningún compromiso posible». 
De todas formas, hay un problema que no se puede subestimar: el líder da forma a las expectativas de sus seguidores y tiene que responder a estas. Muchas veces el populismo se afirma donde hay una amplia desorientación y el deseo de rescate del pueblo encuentra en la retórica del personaje carismático una promesa de redención. En este contexto, similar al caso ruso, se puede hasta hablar de una "dictadura populista" o "autoritarismo populista" (Canovan, 1981, pp. 136-172) que determina un debilitamiento de las instituciones a favor de la personalización de la dimensión política.

Poder fuerte pero sujeto a desgastarse rápidamente porque se legitima de acuerdo con la capacidad de cumplir con las expectativas. Esto implica que la estabilidad interna sea bastante precaria porque deriva principalmente de la coyuntura económica. En un momento de crisis, el apoyo del gobierno puede, por eso, evitar y causar agitaciones sociales. Se determina, así, una situación compleja donde el presidente sabe que su legitimidad y el consenso en el cual puede confiar, derivan de lo que es capaz de ofrecer; como vive en un clima de constante inseguridad, necesita seguir con la centralización política para no perder el control sobre el país. Hasta ahora el partido del presidente se ha aprovechado del nivel de despolitización de la sociedad rusa y ha encontrado el favor de la mayoría con una estrategia que prevé tomar elementos de las diferentes corrientes: liberal en la economía, en temas de izquierda acoge los salarios garantizados y la protección de los empleados, defensa de valores tradicionales cercanos a los conservadores y el discurso patriótico propio de los nacionalistas.

Indudablemente la misma crisis con Ucrania en 2014 ha representado una oportunidad ulterior para utilizar la movilización militar y patriótica y desviar la atención de los problemas internos; con la anexión de Crimea la popularidad del presidente se ha elevado drásticamente. Asimismo, las elecciones parlamentarias de septiembre de 2016 han confirmado el éxito de los partidos secuaces de una política fuerte y clara en favor de la defensa de los intereses nacionales. Si Rusia Unida, el partido del presidente ${ }^{30}$, se ha afirmado con el 54,2\% de los votos, le siguen el partido comunista con el 13,3\%, y el partido liberal-demócrata de la derecha populista con el 13,1\%, confirmando la extrema debilidad de una oposición nosistémica, como las fuerzas liberal-demócratas que una vez más no han superado la barrera del 5\% para entrar al parlamento (Milosevich-Juaristi, 2016). 
Sin embargo, las sanciones económicas infligidas a Moscú por la cuestión ucraniana y la brusca caída del precio del petróleo, han puesto otra vez en tela de juicio las debilidades estructurales de Rusia y las necesarias reformas para la modernización del país.

Esto representa un terreno fértil para las oposiciones que parecen ser aún más populistas que su propio presidente. Si por un lado el líder del partido liberaldemócrata, Vladimir Zhirinovski, es el representante de un nacionalismo xenófobo que no puede considerarse una verdadera alternativa política, más interesante parece el hombre que ha capitaneado las primeras manifestaciones significativas contra Putin entre 2011-2012 y que, en los últimos tiempos, ha regresado al centro de la atención de los medios de comunicación mundial, nos referimos a Aleksej Navalny. 31

Abogado y bloguero ruso, llegó segundo en las elecciones para la alcaldía de Moscú en el año 2013 consolidando su imagen carismática como única posible alternativa al poder de Putin ${ }^{32}$ Si una actitud superficial de los observadores occidentales lleva a considerarlo una esperanza para el cambio político del país, en realidad, un análisis más cuidadoso se puede dar cuenta que su abandono en 2007 del partido liberal pro-occidental Yabloko ha sido consecuencia de un hábil cálculo político, fundado en el convencimiento de que una postura abiertamente liberal y pro-occidental no encuentra el apoyo de la mayoría de los rusos (Lassila, 2016, p. 120). Hasta ahora su programa político parece bastante pobre, centrado principalmente en la lucha anti-corrupción contra el establishment que, indudablemente atrae un gran consenso por parte de la población, sus ideas no son todavía parte de un proyecto claro y bien estructurado que no vaya más allá de una posición nacionalista, en favor de la reconquista de Crimea y de un sistema de visas para los inmigrantes de Asia central, lo cual no significa, de todas formas, una abierta oposición con occidente. Igualmente, sus propuestas económicas alimentan las esperanzas de la población con promesas de aumento de los salarios y de las pensiones, educación gratuita y sistema de salud garantizado.

Si este personaje había sido considerado él solo capaz de disputarle el poder a Putin en las elecciones presidenciales de 2018, apelando al pueblo y presentándose 
como el hombre nuevo después de 18 años de putinismo, en realidad, el Tribunal Supremo Ruso ha inhabilitado su candidatura por sus precedentes judiciales.33 Se entienden, entonces, las perplejidades sobre previsiones optimistas en un escenario que parece seguir igual: instituciones débiles y fuerte personalización del poder; una sociedad donde «bajos niveles de confianza impersonales [en las instituciones] vienen equilibrados por una fuerte confianza interpersonal» (Ledeneva, 2013, p. 11). Desde esta perspectiva, el futuro de Rusia sigue siendo imprevisible porque todavía se encuentra a merced de los programas populistas del hombre que, en un momento histórico, se presenta como el artífice de un cambio radical en el País.

\section{Conclusión}

La consideración de una pluralidad de diferentes experiencias bajo la definición de populismo, concepto, para utilizar las palabras de Taggart (2000, p. 1), "slippery", es decir, viscoso, dificulta los análisis sobre estas cuestiones, empujando cada vez más a contemplar en particular - con el fin de explicar los contradictorios y complejos fenómenos contemporáneos - un puñado de 'ismos'. De hecho, se trata de etiquetas (elitismo, populismo, antielitismo etc.) que a menudo adquieren matices diferentes y/o se superponen, pero que, en general, tienen como punto en común una "relación conflictiva" con la democracia representativa y con la misma conceptualización originaria del fenómeno populista.

Como hemos evaluado a lo largo del presente artículo, el alejamiento de la raíz histórica se manifiesta en la transformación - registrada a lo largo de los años tanto en la variante americana como rusa - del populismo en una forma de propaganda instrumental, a su vez, fundada sobre la retórica necesaria para arrastrar el consenso popular.

De esto se desprende, por lo tanto, la dificultad de encontrar un común denominador en el heterogéneo panorama de los actuales movimientos y tendencias clasificadas como populistas, sin embargo, las evoluciones de este mismo fenómeno permiten identificar algunos elementos claves que los caracterizan, los cuales, entre otros, serían: una relación antagonista entre el pueblo y la élite, con la valorización del primero y una denigración de la segunda, una fuerte personalización del poder por parte de quien se presenta como alternativa a la vieja clase dirigente corrupta, 
el convencimiento de vivir en una época de crisis y ruptura, la hostilidad hacia la política representativa a favor de la democracia directa y la defensa del pueblo considerado, en su totalidad, como algo que se tiene que defender contra enemigos internos y externos. ${ }^{34}$

Bien se entiende, además, que estas complejidades se trasladan del nivel propiamente ideológico al ámbito estructural, o sea, inherente a la ingeniería político-institucional, donde siguen las contraposiciones entre teóricos que observan el indefinido fenómeno populista como una degeneración del sistema liberal-representativo que, así como otras 'formas' políticas, puede adquirir semblanzas diferentes, imponiéndose, por lo tanto, también como una tendencia de largo período; tendencia variable que representa el ámbito en el cual se mueven los analistas que consideran el fenómeno populista como una, entre las varias, modalidad de organización de la arena política. En este sentido, el fenómeno populista tiene que entenderse como un 'momento político', en el cual, en un primer momento, se verifica la acumulación de heterogéneas e insatisfechas instancias del pueblo, lo cual conduce a una separación pueblo/élite, escisión fundamental para crear la condición principal de los movimientos populistas, base sobre la cual, en un segundo momento, se conformará una nueva 'identidad' capaz de representar instancias muy diferentes (Laclau, 2005; Picarella, 2016).

En efecto, aterrizando las reflexiones que acabamos de sintetizar, en los casos presentados en el presente artículo se condensan, según nuestra opinión, todos los rasgos de un fenómeno tan ambiguo como de difícil encasillamiento, ya que, asumiendo claramente las diferencias histórico-políticas y contextuales, así como terminológicas, se puede concluir que, tanto en el caso mexicano como en el ruso, a lo largo de los decenios, se ha producido una metamorfosis del fenómeno populista que ha convertido las iniciales ideologías en tendencias. Estas tendencias no solo reúnen fuertemente los elementos en precedencia mencionados $-\mathrm{y}$ que definitivamente se configuran como componentes básicos del populismo contemporáneo -, sino que ambos casos acumulan elementos referentes a la instauración de una combinación carismática/hiperpresidencialismo, personalización no insertada sobre plataformas bottom-up sino procedente de partidos institucionalizados que, evidentemente, alimentan la delineación de una forma de 'populismo autoritario'. 


\section{Notas}

${ }^{1}$ Para profundizar, entre otros, Picarella (2015).

${ }^{2}$ Que, según Canovan (1999, pp. 2-16), “elimina el pueblo en nombre del pueblo”.

${ }^{3}$ En referencia a la cuestión de la personalización política, se reenvía, entre otros, a Picarella (2014); para lo que se refiere a las dificultades de definición del populismo, véase, entre otros, Taggart (2000); Tarchi (2003); Mény-Surel (2004); Mudde (2004); Roodujin (2014, pp. 572-598); Stanley (2008, pp. 95-110).

${ }^{4}$ En particular, nos estamos refiriendo a la experiencia de 1868 de la Grange, organización impulsada por el gobierno federal que se convirtió para los agricultores en un importante referente de tipo mutualista, a la cual siguió, en 1880, la creación de las Farmer's Alliances, una organización ya de tipo político, claramente ligada a los intereses del campesinado y capaz de conquistar cargos representativos en las asambleas estatales, hasta llegar, en 1892, a la conformación del People's Party que se impuso en el escenario político-partidista como fuerza emergente y cuyo siguiente declive, sin embargo, no eliminará los gérmenes de los ideales populistas. Para profundizar, véase Hofstadter (1960); pueden verse también Pollack (1976); Hicks (1961); Petrone- Picarella (2018).

${ }^{5}$ Para una profundización sobre el populismo ruso, se remite al título 3 del presente artículo.

${ }^{6}$ De todas formas, principalmente de tipo urbano, correspondientemente a la etapa histórica en la cual surgen, a saber después de la crisis de 1929, que teóricamente corresponde con el llamado populismo clásico. Este tipo de configuración será la característica propia de la tradición populista latinoamericana y, según Haya de la Torre, es necesaria para producir el cambio en contra del imperialismo. Para profundizar, véase a Haya de la Torre (1929).

${ }^{7}$ Muy interesante la reflexión de Gino Germani (1965), que identifica en este tipo de populismo el elemento que transborda y caracteriza la transición de la región hacia la modernización, a su vez guiadas por oligarquías unificadoras cuyo poder 
fue favorecido por la combinación anomia/movilización/escasos recursos, una mezcla que, por lo tanto, predispone fácilmente las masas a la manipulación.

${ }^{8}$ Interesante en este sentido el análisis de Ianni $(1975 ; 1990)$, según el cual los procesos de urbanización y de industrialización llevaron a la constitución de nuevos valores que suplantaron los viejos ideales de tipo comunitario. Propiamente, sobre la base de este proceso de secularización, es posible indagar las relaciones de clases, que llevarían al análisis del populismo de las élites burguesas y de su capacidad de manipulación de las masas, y también al estudio del populismo de masas y de su carácter revolucionario.

${ }^{9}$ Proclamado en noviembre de 1911, el Plan Ayala detalla el núcleo programático de la rebelión agraria: restitución de las tierras, reparto de las mismas, indemnización y, propiamente por esta razón, es conocido como el manifiesto de la lucha zapatista.

${ }^{10}$ Rápidamente, esta Constitución garantizaba derechos en materia de seguridad social, así como en materia de educación, previendo laicidad y gratuidad. Igualmente, en el ámbito del derecho laboral y sindical, estableciendo la jornada laboral de 8 horas, y en materia agraria, reconociendo a los campesinos el reparto agrario, los ejidos y las comunidades. Para profundizar, véase, La Constitución mexicana de 1917, UNAM, México, 1982.

${ }^{11}$ El segundo decenio del siglo XX caracterizó a México por la gran revolución popular con el campesinado, que protagonizó los tres más relevantes ejércitos revolucionarios (zapatistas, villistas, obregonistas), evidenciando además una perfecta combinación entre luchas campesinas y nuevas luchas obreras, que desató el impetuoso torbellino revolucionario. Sobre la revolución mexicana, véase entre otros, Morales Jiménez (1986).

12 Según Bazant (1982, p. 168) "La expropiación de la industria petrolera perteneciente a extranjeros hizo popular a Cárdenas con todas las clases sociales y le ganó la estatura de un héroe nacional, pero en realidad fue su reforma agraria la que tuvo el impacto más profundo sobre la tradicional estructura social de México y la que más que cualquier otra medida consumó, después de casi dos décadas de reveses, las metas sociales de la Revolución y de la Constitución de 1917”. 
13 "El contexto en el cual tendrá lugar el populismo de Cárdenas es definible como abiertamente autoritario por varias razones, quizá la más importante porque la consolidación de un régimen de corte autoritario fue la salida que encontraría disponible para controlar y amortiguar definitivamente tres procesos simultáneos que se le presentaban en su horizonte político: a) poner punto final a la violencia estrictamente política que, por su parte, había sido el motor principal de la llamada primera etapa de la Revolución Mexicana; b) poner punto final a la violencia selectiva que se estaba generando en el interior del propio grupo ganador del período armado, pero también con el ascenso a la vida pública de grupos que con anterioridad no estaban presentes, como lo fue la experiencia del catolicismo activo y posteriormente radicalizado; c) poner punto final al papel definitorio que jugaría Plutarco Elías Calles hacia finales de los años veinte en la creación del PNR, y donde más que Calles, Cárdenas jugaría igualmente un papel decisivo" ( Cansino- Covarrubias, 2006, p. 69).

14 Se encasillan en esta categoría, también Carlos Menem en Argentina (19891999); Fernando Collor de Melo en Brasil (1990-1992); Alberto Fujimori en Perú (1990-2000). Para profundizar sobre el neopopulismo, véase entre otros Loaeza (2001, p. 365-386; Weyland, 1999; Weyland, 2001; Weyland, 2003).

15 Esta corriente se ha desarrollado fuertemente en Europa a partir del último cuarto del Siglo XX, y se fundamenta claramente sobre una ideología fuertemente xenófoba y racista, sobre un lenguaje de visible enfrentamiento al Estado, a la institucionalidad, al establishment en general. Para profundizar, Mouffe (2009); Surel (2001); Mayer (2001); Mastropaolo (2005).

${ }^{16}$ El presidente Peña Nieto centró toda su campaña sobre técnicas de marketing políticos que enfocaban hacia las promesas cumplidas. La proyección de esta imagen, fue apoyada por dos eslogan en particular ( "Este es mi compromiso y tú sabes que lo voy a cumplir" y "Te lo firmo y te lo cumplo" ) y sobre todo por la red, a través de trending topics y bots, que amplifican la presencia de un candidato en internet. Una estrategia fuertemente personalizada que, por otro lado, provocó el surgimiento del movimiento ciudadano Yo Soy 132 por la libertad y la mayor democratización de los medios de comunicación.

${ }^{17}$ Sobre la historia rusas en esos años, véase Malia (1961). 
${ }^{18}$ Cabe destacar la distancia entre el bolchevismo y estos pensadores revolucionarios que no proponían una trasformación capitalista de la economía del imperio; de lo contrario, estaban convencidos que la reorganización de la sociedad tenía que fundarse en la obščina, la tradicional comuna campesina, punto de partida de una nueva organización colectiva de la tierra fundada en el autogobierno. Para los primeros populistas es entonces el campesino el primer artífice del cambio de la sociedad rusa, mientras que el proletariado jugaba un papel bastante marginal. Para profundizar estos aspectos, véase Scocozza (2010, pp. 73 y ss).

${ }^{19}$ Sobre la potencialidad revolucionaria de Rusia en oposición a la decadencia europea después de 1848, véase una de las más famosas obras de Aleksandr Herzen (1956).

${ }^{20}$ Sobre la revista véase, entre otros, Ejdel'man (1963); Williams (2001, pp. 115-132).

${ }^{21}$ Véase las conclusiones a las cuales llega Venturi (1962, pp. 952-962).

22 Para profundizar el pensamiento ruso en esos años, véase Berlin (1979); Walicki (1975).

${ }^{23}$ Recordamos que Serno-Solovévic fue deportado y luego matado en Siberia en 1866.

${ }^{24}$ Para profundizar la historia rusa durante el reinado de Alejandro II, más allá de los textos generales ya mencionados, véase Eklof -Bushnell -Zakharova (1994).

${ }^{25}$ Según la opinión de Seton-Watson (1971, p. 386).

${ }^{26}$ Sobre estas páginas de la historia zarista, véase también Daly (1998).

${ }^{27}$ El uso de esta palabra empezó a afirmarse con la victoria de Boris Yeltsin, acusado de utilizar las herramientas de la demagogia y del populismo en contraposición a un personaje como Michail Gorbachov que, fundando su acción política en un camino gradual y a menudo impopular, no logró contar con suficiente apoyo y simpatía entre los rusos (Ulianova, 2003, pp. 170 y ss).

${ }^{28}$ Sobre el autor, véase Scocozza (2003); en ruso, véase AA. VV. (1993); Kosik (1997). 
${ }^{29}$ Doctrina elaborada por Vladislav Surkov; véase Surkov (2006).

${ }^{30}$ Cabe destacar que, en las últimas elecciones presidenciales, en marzo de 2018, el partido de gobierno ha decidido respaldar la candidatura del presidente, a pesar de la decisión de Putin de presentarse como independiente para alejarse de la imagen del partido que ha debido enfrentar numerosas acusaciones de corrupción.

${ }^{31}$ De hecho, por haber liderado nuevas manifestaciones contra Putin ha sido condenado a 30 días de cárcel. Véase "Policía rusa detiene a más de mil manifestantes partidarios del principal opositor a Putin", en http://www.huffingtonpost.com. $\mathrm{mx} / 2017 / 06 / 13 /$ policia-rusa-detiene-a-mas-de-mil-manifestantes-partidariosdel_a_22140110/, 13 de junio de 2017.

${ }^{32}$ Sobre este personaje, véase Lassila (2016, pp. 118-137).

${ }^{33}$ Véase El Supremo Tribunal ruso confirma la prohibición a Alexei Navalny de concurrir a elecciones, 18 de enero de 2018, en http://www.elmundo.es/ internacional/2018/01/06/5a50ba7ce5fdeacf178b4668.html.

${ }^{34}$ Entre otros, sobre estos elementos vease Tarchi (2003, pp. 13 y ss.).

\section{Referencias}

AA. VV. (1993). K. Leont'ev, naš sovremmenik (K. Leont'ev, nuestro contem poráneo). S. Petersburgo: Izd-vo Černyševa.

Bazant, J. (1982). Breve historia de México. De Hidalgo a Cárdenas (18051940), $3^{a}$ edición. México: Premia Editora.

Berlin, I. (1961). "Il populismo russo", en Tempo presente, pp. 9-10.

Berlin, I. (1979). Russian Thinkers. New York: Penguin Book.

Canovan, M. (1981). Populism. New York-London: Harcourt Brace Jovanovich.

Canovan, M. (1999). "Trust the People! Populism and the Two Faces of Democra cy”, en Political Studies, Vol. 47, No. 1, pp. 2-16. 
Cansino, C. - Covarrubias, I. (2006). En el nombre del pueblo. Muerte y resurrección del populismo en México. México: Universidad Autónoma de Ciudad Juárez, Centro de Estudios de Política Comparada.

Casula, P. (2013). “Sovereign Democracy, Populism, and Depoliticization in

Russia: Power and Discourse during Putin's First Presidency", en Problems of Post-Communism, 3, pp. 3-15.

Córdova, A. (1974). La política de masas del cardenismo. México: Ediciones Era.

Daly, J. W. (1998). Autocracy under Siege: Security Police and Opposition in Russia: 1866-1905. DeKalb: Northern Illinois University Press.

Ejdel'man, N. Ja. (1963). Gercenovskij "Kolokol" (El "Kolokol” de Herzen). Moscú: Učebno-pedagogičeskoe izd.

Eklof, B. - Bushnell, J. - Zakharova, L. (1994). (a cargo de). Russia's Great Reforms, 1855-1881. Bloomington and Indianapolis: Indiana University Press.

Germani, G. (1965). "Democracia representativa y clases populares en América Latina", en A. Touraine y G. Germani, América del Sur: un problema nuevo, Barcelona: Nova Terra.

Haya de la Torre, V. R. (1929). El antimperialismo y el APRA. Perú: LibreríaEditorial J. Mejía Baca.

Hennessy, A. (1970). “América Latina”, en G. Ionescu y E. Gellner Ionescu, Populismo. Sus significados y características nacionales: Buenos Aires: Amorrortu editores.

Herzen, A. (1956). From the other shore and the Russian People and the Socialism. New York: Breziller.

Hicks, J. D. (1961). The Populist Revolt. A History of the Farmers'Alliance and the People's Party. USA: University of Nebraska Press. 
Hofstadter, R. (1960). The Age of Reform. From Bryan to F.D.R. New York: Vintage.

Ianni, O. (1975). La formación del Estado populista en América Latina. México: Ediciones Era.

Ianni, O. (1990). "La idea de América Latina", en M. Roitman y C. Castro-Gil, América Latina: entre los mitos y la utopía, Madrid: Editorial Universidad Complutense.

Kazin, M. (1995). The Populist Persuasion. An American History. New York: Basic Books.

Kosik, V. I. (1997). Konstantin Leont'ev: razmyšlenija na slavjanskuju temy (K. Leont'ev: reflexión sobre el tema eslavo). Moscú: Zercalo.

Laclau, E. (2005). La razón populista. Buenos Aires: FCE.

Lassila, J. (2016). “Aleksei Naval'nyi and Populist Re-ordering of Putin's Stability", en Europe-Asia Studies, 1, pp. 118-137.

Ledeneva, A. (2013). Can Russia Modernise? Sistema, Power, Networks and nformal Gobernance. Cambridge: Cambridge University Press.

Loaeza, S. (2001). “La presencia populista en México", en G. Hermet - S. Loaeza - J. F. Prud'homme (comps.), Del populismo de los antiguos al populismo de los modernos. México: El Colegio de México.

Malia, M. (1961). Alexander Herzen and the Birth of Russian Socialism (18121855). Cambridge: Harvard University Press.

Mastropaolo, A. (2005). La mucca pazza della democracia. Torino: Bollati Boringhieri.

Mayer, N. (2001). "Los campeones de las extremas derechas europeas", en G. Hermet et al., Del populismo de los antiguos al populismo de los modernos. México: Colegio de México. 
Mény, Y. - Surel, Y. (2004). Populismo e democrazia. Bologna: Il Mulino.

Milosevich-Juaristi, M. (2016). Las elecciones parlamentarias rusas de septiembre de 2016, 21 de septiembre de 2016, en http://www.realinstitutoelcano.org/ wps/portal/web/rielcano_es/contenido?WCM_GLOBAL_CONTEXT=/ elcano/elcano_es/zonas_es/ari68-2016-milosevich-las-elec ciones-parla mentarias-rusas-de-septiembre-de-2016, consultado el 20 de mayo de 2017.

Morales Jiménez, A. (1986). Maestros de la Revolución Mexicana. México:

INEHRM, Instituto Nacional de Estudios Históricos de la Revolución Mexicana.

Mouffe, C. (2009). "El 'fin de la política' y el desafío del populismo de derecha", en F. Panizza (comp.), El populismo como espejo de la democracia. Buenos Aires: FCE.

Mudde, C. (2004). “The Populist Zeitgeist”, en Government and Opposition, 39/3.

Oliker, O. (2017). "Putinism, Populism and the Defence of Liberal Democracy", en Survival, 1.

Petrone, A. - Picarella, L. (2018). “El Trump de «make America great again»: ¿una ulterior variante populista? “, en Revista Pensares y Quehaceres, $\mathrm{n}^{\circ}$ 5 , año 3 .

Picarella, L. (2014). De la transición al zapaterismo: la evolución del sistema político español entre presidencialización y personalización. Bogotá: Edi torial Planeta.

Picarella, L. (2015). "Sobre los conceptos de representación política, participación política y populismo: una lectura", en Frónesis. Revista de filosofía jurídica, social y política, Facultad de Ciencias Jurídicas y Políticas, Universidad del Zulia, Venezuela, vol. 22, n. 2, mayo-agosto, pp. 22-51. 
Picarella, L. (2016). "De la personalización política al "redescubrimiento" de la dimensión del orden común”, en A. Scocozza- G. D’Angelo (eds.), Magister et discipuli: filosaofia, historia, política y cultura. Bogotá: Penguin Random House.

Pollack, N. (1976). The Populist Response to Industrial America. Midwestern Populist Thought. Cambridge: Harvard University Press.

Roodujin, M. (2014). "The Nucleus of Populism: In Search of the Lowest Common Denominator", en Government and Opposition, 4, pp. 572-598.

Scocozza, C. (2003). “The Slavs, Russia and Europe: reviewing K. Leontiev today”, en AA. VV. Tradycja Lacinska I Bizantyjska Wobec Idei Jednosci Europejskiej (La tradición latina y bizantina frente a la idea de la unidad europea). Gniezno: Collegium Europaeum Gnesnense.

Scocozza, C. (2010). Aleksandr Herzen e il Risorgimento Italiano. Milano: Mimesis.

Scocozza, C. (2017). "Entre autoritarismo y democracia. El caso de Rusia", en L. Picarella y C. Scocozza (a cargo de), Democracia y Procesos Políticos en América Latina y Europa. Bogotá: Penguin Random House.

Seton-Watson, H. (1971). Storia dell'impero russo (1801-1917). Torino: Einaudi.

Stanley, B. (2008). “The Thin Ideology of Populism”, en Journal of Political Ideologies, 1, pp. 95-110.

Surel, Y. (2001). "Populismo y sistemas de partidos en Europa" y N. Mayer "Los campeones de las extremas derechas europeas", en G. Hermet et al., Del populismo de los antiguos al populismo de los modernos. México: Colegio de México.

Surkov, V. (2006). "Natsionalizatsiia buduščego" (la nacionalización del futuro), en Ekspert, 20 de noviembre. 
Taggart, P. (2000). Populism. Buckingham: Open University Press.

Tarchi, M. (2003). L'Italia populista. Dal qualunquismo ai girotondi. Bologna: Il Mulino.

Ulianova, O. (2003). “Experiencias Populistas en Rusia”, en Revista de Ciencia Política, 1.

Venturi, F. (1972). Il populismo russo. Torino: Einaudi.

Venturi, F. (1962). “Alessandro Herzen ( a 150 anni dalla nascita)”, en Il Ponte, 1962, 7, pp. 952-962.

Walicki, A. (1975). The slavophile controversy: history of a conservative utopia in ninetheen century russian thought. Oxford: Clarendon Press, Oxford.

Weyland, K. (1999). "Neoliberal Populism in Latin American and Eastern Europe", en Comparative Politics, Jul., vol. 31, núm. 4;

Weyland, K. (2001). "Clarifying a Contested Concept: Populism in the Study of Latin American Politics", en Comparative Politics, Oct., vol. 34, núm.1.

Weyland, K. (2003). "Neopopulism and Neoliberalism in Latin América: How Much Affinity?", en Third World Quarterly, Dec., vol. 24, núm. 6.

Williams, H. (2001). "Ringing the Bell. Editor-reader dialogue in Alexander Herzen's Kolokol”, en Book History, 4, pp. 115-132.

Zanatta, L. (2004). "Il populismo in America Latina", en Filosofia Politica, n. 3, dicembre.

Zanatta, L. (2013). Il populismo. Roma: Carocci.

Zermeño, S. (1996). La sociedad derrotada. México: Siglo XXI. 